Schneider, J. (1953. Bulletin de la Société de Pathologie Exotique et de ses Filiales, 46, 1016.

Stavitsky, A. B. (1966). Milinary Medicine, 131, 1167.

Taliaferro, W. H., and Mulligan, H. W. (1937). Indian Medical Research . ., and Mullic

Thijssen, J. H. H., de Waard, F., and Wiersinga, A. (1967). Lancet, 1, 814.

Travis, R. H., and Sayers, G. (1965). In The Pharmacological Basis of Therapeutics, 3rd ed., p. 1608, edited by L. S. Goodman and A. Gilman. New York, Macmillan.

Trowell, H. C., and Vaizey, J. M. (1956). Lancet, 2, 1281.

Vandepitte, J. M. (1949). Annales de la Société Belge de Médecine Tropicale, 29, 501 .
Voller, A., and Bray, R. S. (1962). Proceedings of the Society of Experimental Biology and Medicine, 110, 907.

Walsh, S. D., and Clark, F. R. (1967). Scottish Medical fournal, 12, 302.

Warrell, D. W., and Taylor, R. (1968). Lancet, 1, 117.

Waters, A. H., and Mollin, D. L. (1961). Fournal of Clinical Pathology, $14,335$.

Wurl, O. A., Gillespie, J. O., and Beisel, W. R. (1952). United States Armed Forces Medical fournal, 3, 1347.

Zoutendyk, A., and Gear, J. (1951). South African Medical fournal, 25, 665

Zuckerman, A. (1966). Military Medicine, 131, 1201.

\title{
Deaths in Children with Acute Appendicitis
}

\author{
H. G. PLEDGER,* M.D., F.F.A. R.C.S. ; R. BUCHAN, $\dagger$ M.D., F.R.C.s.
}

British Medical fournal, 1969, 4, 466-470

\begin{abstract}
Gummary : Two hundred and four children died of acute appendicitis in England and Wales in the five-year period 1963-7. The mortality rate in children less than 5 years old was eight times higher than that in those aged 5-14. It is suggested that diagnosis, intravenous therapy, treatment of convulsions and hyperpyrexia, and anaesthesia are fields where there is room for improvement in management. Moreover, there is a place for the wider use of national medical audits on the lines of the Confidential Enquiry into Maternal Deaths.
\end{abstract}

\section{Introduction}

About 40 children die each year of acute appendicitis in England and Wales, representing about one death for every 780 hospital admissions with this diagnosis. It is tempting to feel that this number is virtually irreducible, but a previous limited survey by us suggested that in many children there are still avoidable factors contributing to death. We therefore decided to obtain information about all the children certified as dying of acute appendicitis in England and Wales during the fiveyear period 1963-7.

\section{Method}

We bought from the Registrar General a copy of the death certificates of children up to age 15 years whose death had been coded in I.C.D. Codes 550, 550.1, and 551. In these groups 229 deaths were coded, and we received this number of certificates. We extracted all certificates with a manifestly incorrect diagnosis, such as perforated caecum in neonates, and 18 which showed that the child had died at home. We then wrote to the records officer of the hospital concerned asking him to forward an enclosed letter to the consultant under whose care the child had been admitted. In this letter we set out the purpose of our investigation and asked for loan of the case notes or for some information about the patient. If we received no reply within two months we sent a second letter, and if there was still no reply we wrote to the local coroner if the death had been reported to him. In a number of instances we wrote a further letter to the hospital doctor asking for more details.

- Consultant Anaesthetist, Royal Aberdeen Children's Hospital and Aberdeen Royal Infirmary. At present: Assistant Senior Medical Aberdeen Royal Infirmary. At present: Assistant Senior Medic

Officer, Oxford Regional Hospital Board, Headington, Oxford.
t Surgical Registrar, Royal Aberdeen Children's Hospital and Aberdeen Royal Infirmary. At present: Senior Registrar, Professorial Surgical Unit, Cardiff Royal Infirmary.

\section{Results}

We wrote to hospitals regarding 200 children and eventually had a reply about 197 . The sources of information on which the subsequent data are based are shown in Table I.

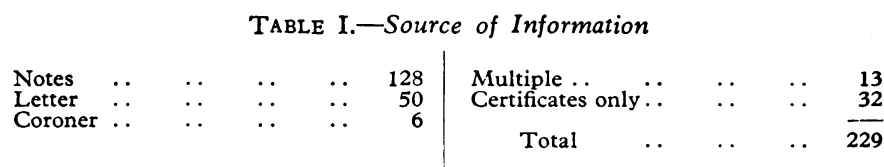

Incorrect Certification.-After we examined the 229 death certificates together with the replies to our inquiries we concluded that 25 were not "acute appendicitis deaths," which for the purpose of this survey we have defined as deaths resulting from acute appendicitis or an immediate complication of this disease, from a disease treated as acute appendicitis, or from a complication of the treatment of either of these groups. The correct diagnoses in these 25 patients are shown in Table II

TABLE II.-Diagnosis in.25 Cases Incorrectly Certified as Dying of Acute Appendicitis

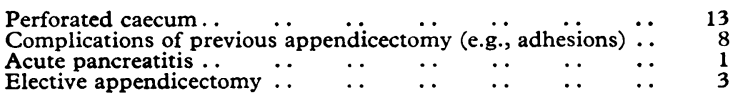

"Acute Appendicitis Deaths."-Two hundred and four children came into this category, and Table III shows the number dying in each of the years we studied.

TABLE III.-Number of Children Dying of Acute Appendicitis in England and $W$ ales, by Year of Death

\begin{tabular}{ll|c|c|c|c|c|c}
\hline Year $\ddot{~}$ & $\ldots$ & 1963 & 1964 & 1965 & 1966 & 1967 & Total \\
No. of children & $\cdots$ & 37 & $\mathbf{4 0}$ & 52 & $\mathbf{4 4}$ & 31 & 204
\end{tabular}

Figs. 1 and 2 and Table IV give information about admissions and deaths, and show the deaths per 1,000 for each sex, for two age groups, and for year of admission. The admission figures were obtained from the hospital inpatient inquiry (the data for 1967 are not yet available). Throughout the rest of this paper, when appropriate, we will give details for the age groups $0-4$ years and 5-15 years. These results show very clearly the considerably higher death rate in the younger children. Though the under 5's make up only $7 \%$ of admissions they account for $37 \%$ of the deaths. The mortality rates 
given are probably slightly low because some of the admissions given this diagnosis may have been suffering from another disease.
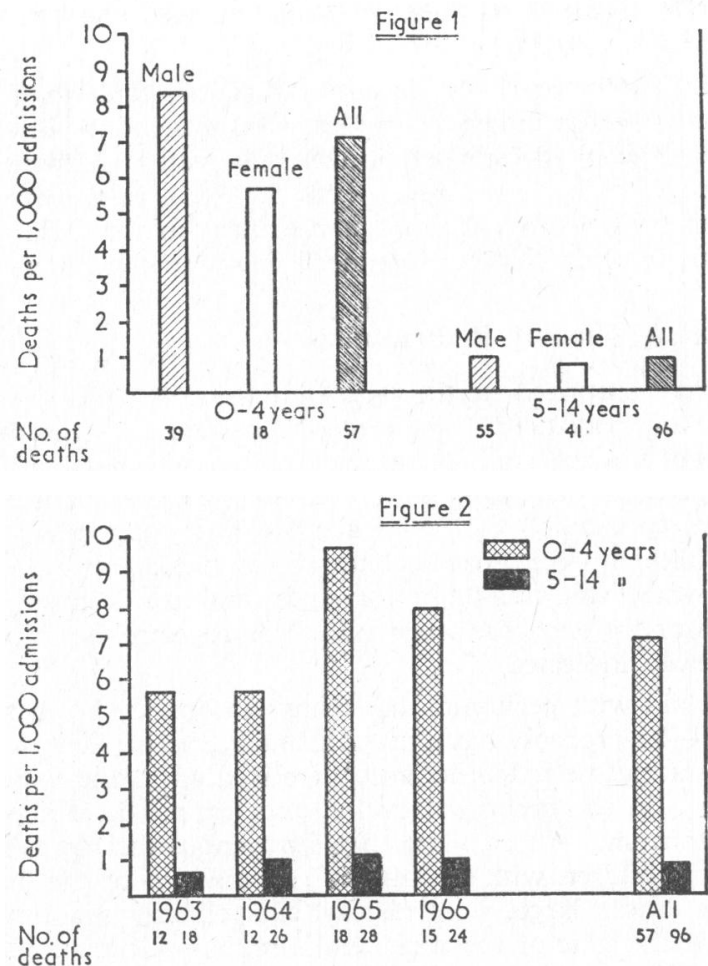

FIG. 1.-Age and sex incidence of children with acute appendicitis dying in hospital. England and Wales 1963-6.

FIG. 2.-Death rate by year of children with acute appendicitis dying in hospital in England and Wales, 1963-6.

\begin{tabular}{l}
$\begin{array}{r}\text { TABLE IV.-Hospital Deaths and Admissions in Children with a } \\
\text { Diagnosis of Acute }\end{array}$ \\
$\begin{array}{l}\text { Appendicitis } \\
\text { in England and Wales }\end{array}$ 1963-6 \\
\hline
\end{tabular}

Deaths Outside Hospital.-Of the 204 children dying of "acute appendicitis," 23 (11\%) died outside hospital-18 at home and 5 during their journey to hospital; 13 of these children were aged less than 5 .

Deaths in Hospital.-The pathological lesions in the 181 children who arrived at hospital alive but who subsequently died are given in Table $\mathrm{V}$. We refer later to those children who did not have peritonitis. For four children we had no information other than the death certificate (three no reply, one notes destroyed), and thus 177 children are considered in more detail.

TABLE V.-Pathological Lesion in Patients Dying in Hospital of

\begin{tabular}{|c|c|c|c|c|c|}
\hline & & & & \multirow{2}{*}{$\begin{array}{c}\text { All Ages } \\
146 \\
10 \\
14 \\
9 \\
2\end{array}$} & \multirow{2}{*}{$\begin{array}{c}\text { Under } 5 \text { Years } \\
(65) \\
(3) \\
(2) \\
(0) \\
(1)\end{array}$} \\
\hline $\begin{array}{l}\text { Acute appendicitis with } \\
\text { Acute appendicitis with } \\
\text { Acute appendicitis } \\
\text { Other abdominal disease } \\
\text { Respiratory disease }\end{array}$ & $\begin{array}{l}\text { onitis } \\
\text { ess } \\
\cdots \\
\cdots \\
\cdots\end{array}$ & $\begin{array}{l}\because \\
\because \\
\therefore\end{array}$ & $\begin{array}{l}\because \\
\because \\
\therefore\end{array}$ & & \\
\hline Total & .. & . & $\cdots$ & 181 & (71) \\
\hline
\end{tabular}

Children Dying without Operation.-Thirty-one children died without having a laparotomy (18 of these were under 5). The apparent reason for this is given in Table VI. There is inevitably some overlap between these groups. We have placed children in the "not diagnosed" group only where diagnostic difficulty or delay so affected management as to be a contributory cause in the child's death. In several children who were moribund on admission or were thought to be too ill for operation, the quantity, type, and route of fluid used for resuscitation appears to have been inadequate. We discuss this in more detail later.

TABLE VI.-Apparent Reason for No Operation in Children Dying in Hospital of "Acute Appendicitis"

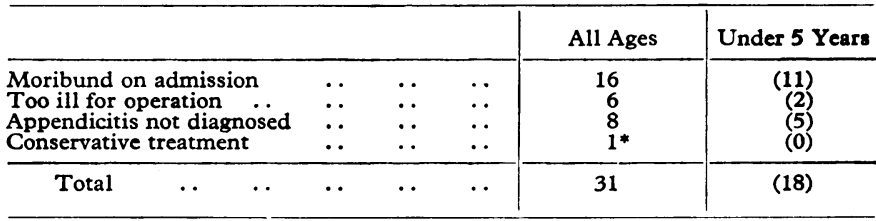

* Acute leukaemia.

Operative and Postoperative Deaths.-We have details of 146 children who died during or after an operation. The time of death is shown in Table VII (children dying of cerebral damage sustained during an episode of cardiac arrest during operation have been included in deaths during anaesthesia). Overall, 96 deaths $(66 \%)$ occurred either during anaesthesia or within the first 48 hours postoperatively, and $40(78 \%)$ of the younger children died during this period.

TABLE VII.-Time of Death in Relation to Operation

\begin{tabular}{|c|c|c|c|c|c|}
\hline & & & & All Ages & Under 5 Yeara \\
\hline $\begin{array}{l}\text { During anae } \\
\text { First or seco } \\
\text { Third or fou } \\
\text { Fifth, sixth, } \\
\text { Later ... }\end{array}$ & $\begin{array}{l}\text { esia } \ldots \\
\text { day postop } \\
\text { day posto } \\
\text { seventh da } \\
\ldots \quad \ldots\end{array}$ & 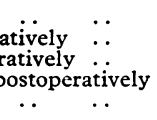 & $\begin{array}{l}\because \\
\because \\
\because \\
\therefore\end{array}$ & $\begin{array}{r}25 \\
71 \\
9 \\
16 \\
25\end{array}$ & $\begin{array}{r}(9) \\
(31) \\
(1) \\
(5) \\
(5)\end{array}$ \\
\hline Total & .. & . & . & 146 & (51) \\
\hline
\end{tabular}

Factors Contributing to Death.-It is never easy to define precisely why a patient dies, and this is especially so in a study of case histories. We felt, however, that we had enough details to outline some contributory factors, and Table VIII gives these for the 146 patients ( 51 under 5 years) dying during or after operation. In some patients more than one factor was responsible, and in these instances both have been recorded.

TABLE VIII.-Factors Contributing to Death of Children Dying Durine or After Operation

\begin{tabular}{|c|c|c|c|c|c|}
\hline & & & & All Ages & Under 5 Yeara \\
\hline 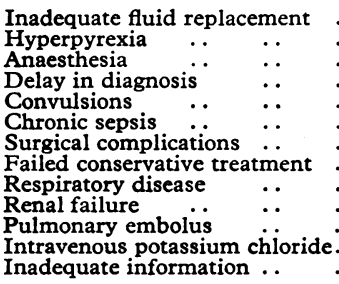 & $\begin{array}{l}\because \\
\therefore \\
\therefore \\
\therefore \\
\therefore \\
\therefore \\
\therefore \\
\therefore \\
\therefore\end{array}$ & $\begin{array}{l}\ldots \\
\cdots \\
\cdots \\
\cdots \\
\cdots \\
\cdots \\
\cdots \\
\cdots \\
\cdots\end{array}$ & $\begin{array}{l}\because \\
\because \\
\because \\
\because \\
\because \\
\because \\
\because \\
\because\end{array}$ & $\begin{array}{r}54 \\
19 \\
19 \\
16 \\
13 \\
13 \\
6 \\
5 \\
5 \\
2 \\
1 \\
1 \\
44\end{array}$ & $\begin{array}{r}(25) \\
(5) \\
(5) \\
(7) \\
(8) \\
(1) \\
(1) \\
(0) \\
(2) \\
(0) \\
(0) \\
(1) \\
(14)\end{array}$ \\
\hline
\end{tabular}

The following are definitions of factors included in Table VIII inadequate fluid replacement: A child with peritonitis who (a) received no intravenous therapy, or none until an episode of cardiovascular collapse, $(b)$ was given less than his normal daily fluid requirements to treat dehydration, (c) was given no intravenous colloid in the presence of oligaemic shock, or (d) had abnormal serum urea or electrolytes. Hyperpyrexia: A temperature recorded as $40.5^{\circ}$ C. $\left(105^{\circ}\right.$ F.) or over. Chronic sepsis: Evidence of pelvic, subphrenic, or other intra-abdominal abscess. Surgical complications : Haemorrhage, leaking appendix stump, bowel perforation. Failed conservative treatment: Patients with a hospital diagnosis of acute appendicitis who were deliberately managed conservatively until the development of generalized peritonitis.

Deaths in Patients without Peritonitis (at primary operation). -Of the 177 children who died in hospital, and for whom we 
have some information, $35 \mathrm{did}$ not have peritonitis at their primary operation. The pathological lesion in these children is given in Table V. Of these 35 children 24 had appendicitis without peritonitis, 2 had mesenteric adenitis, 2 respiratory disease, 1 a ruptured lutein cyst, and in 6 there was no detectable pathology. All had appendicectomy performed. Some of the factors contributing to death in these 35 patients are given in Table IX. Three of the children with surgical complications had a leaking appendicectomy stump and two had an intraperitoneal haemorrhage. Three children with unexplained postoperative peritonitis had no evidence of bowel perforation at subsequent laparotomy. One of the children with respiratory disease has a haemorrhagic pneumonia ; the other had "acute asthma." Neither of these children was severely ill, and both died suddenly, the first during anaesthesia.

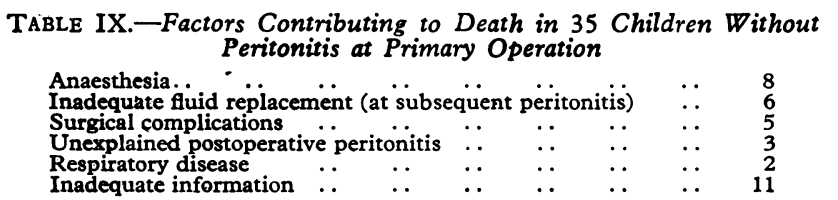

Summary of Acrte Appendicitis Deaths.-The preceding paragraphs are summarized in Table X.

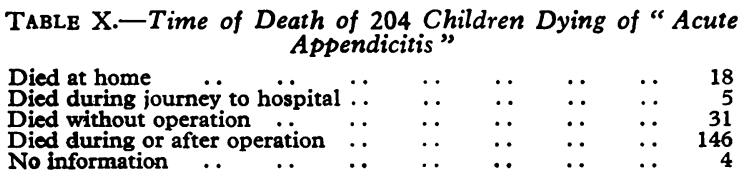

\section{Discussion}

The number of children dying each year of acute appendicitis is now low, but the vast majority of these deaths occur in normal healthy children suffering from an acute illness from which they should recover. When one realizes that the national mortality rate in the younger children during the period 1963-6 is worse than that being achieved by Mason Brown in 1950-4 (Mason Brown, 1956) it is obviously worth looking for aspects of management where improvements can be made, especially as for every death there must be several "near misses."

\section{Diagnosis}

Diagnosis Outside Hospital.-We have shown that 23 children died outside hospital and a further 16 were moribund on admission ; of the younger children, almost one-third died during these periods. This reflects the difficulties for parents and family doctors in recognizing the disease in the small child, and reinforces the points made by Jackson (1963), who looked at the problem in detail. We did not attempt to obtain more information about these children, as it would have caused unjustifiable distress to their parents, and it would not have been possible to obtain the detailed information in Jackson's valuable paper.

Diagnosis in Hospital.-In 24 patients (13 under 5 years) delay in diagnosis in hospital played some part in the fatal outcome. Respiratory infections, gastroenteritis, or mesenteric adenitis were the main alternative diagnoses. Four of the children were admitted to infectious disease hospitals and subsequently had to be transferred to a general hospital when the correct diagnosis became apparent. To make a correct diagnosis in the child with acute abdominal symptoms may be extremely difficult and Winsey and Jones (1967) have looked at this problem in depth. Good training and a constant suspicion of acute appendicitis (Mason Brown, 1962) are of prime importance.

\section{Deaths in Patients without Peritonitis Initially}

Fifteen of the children in this category in our survey died as the result of technical errors on the part of the anaesthetist or surgeon, and we considered that most of the other 20 deaths were possibly avoidable.

Howie (1966) has shown in adults that it is safer to remove a normal appendix rather than to leave a diseased one. Provided that the surgeon, anaesthetist, and nursing staff are experienced in the care of children (Mason Brown, 1956), we believe that operation is the correct line of management in the child when suspicion remains that the diagnosis may be appendicitis.

\section{Intravenous Therapy in Peritonitis}

We were surprised at the large number ( 54 children) with evidence of inadequate fluid replacement and at some of the methods of therapy applied. Some children with good evidence of preoperative dehydration were given no intravenous fluids until an episode of cardiovascular collapse postoperatively; other children were given subcutaneous fluids, or even oral fluids, when vomiting copiously: Several were given large amounts of $5 \%$ dextrose when colloid and electrolyte solutions were clearly indicated.

The child with peritonitis has many reasons for being fluiddepleted-he probably has a reduced intake, he is likely to have been vomiting, he is febrile, and there is fluid in the lumen of the bowel, in the peritoneal cavity, and trapped in oedema of the peritoneum. We consider that intravenous therapy is mandatory in children with peritonitis. Assessment of the patient must be based largely on history and clinical examination, including the state of the peripheral circulation, the amount of venous filling, and the urinary output. Too much reliance should not be placed on pulse rate or blood pressure, as pulse rate will be affected by temperature, and arterial hypotension is a late sign of oligaemia in children. In some patients packed cell volume, serum urea, electrolytes, central venous pressure, and acid-base status will need measuring as a guide to management.

Whether intravenous therapy should be begun preoperatively or started after induction of anaesthesia, when it is technically easier, must be determined by deciding if there is preoperative dehydration. As anaesthesia reduces some of the body's compensatory mechanisms, if there is doubt it is preferable to err on the side of giving fluids early. The child with signs of oligaemia or established dehydration must be adequately resuscitated before operation.

If there is evidence of oligaemia then expansion of the intravascular compartment should be undertaken before giving water and electrolytes. We feel that dextran 70 is the fluid of choice, as it is probably inadvisable to give whole blood to patients who are already haemoconcentrated, when an improvement in capillary flow is the objective. It seems to us that in the early stages replacement of both water and electrolytes is necessary and may be achieved with solutions such as Ringer lactate. Subsequent therapy may be guided by clinical assessment, serum electrolytes, urinary output, and a knowledge of the fluid requirements of children.

A surprisingly large number of children were given intravenous pressor drugs, even in the later years of this survey. The evidence that $\alpha$ stimulators are harmful in shock is now considerable (Lillehei et al., 1964) and we consider that they have no place in the management of peritonitis. The place of drugs such as dibenzyline and isoprenaline in the management of "resistant shock" is not yet clear and is outside the scope of an article such as this. They certainly have no place in the management of the vast majority of patients with oligaemic or bacteraemic shock (Weil and Shubin, 1967), who primarily need expansion of blood volume.

While it is obviously desirable that each patient should be treated on an individual basis we feel that there may on occasion 
be a place for empirical treatment, as is advocated for burns. We suggest that a child with evidence of oligaemia should receive a rapid infusion of $20 \%$ of his blood volume as dextran 70. As blood volume in children is about $80 \mathrm{ml} . / \mathrm{kg}$ body weight the amount of dextran given should be $15 \mathrm{ml} . / \mathrm{kg}$. This should be followed with a solution such as Ringer lactate, the requirements for 24 hours to be given in two to four hours and a similar amount in the next 6 to 12 hours, depending on clinical assessment. A less severely ill child might be assumed to be depleted of 24 hours' fluid intake, and this could be replaced over eight hours, to be followed by a slower rate of maintenance therapy.

Careful clinical observation and a knowledge of fluid replacements in children are the key to rational therapy, coupled with an awareness of the possibility of large hidden losses in peritonitis (Randall et al., 1967). We have the impression from a number of case histories that sudden cardiovascular collapse may occur in dehydration, especially on the first postoperative day, and that this is more easily prevented than treated.

We found many examples of inadequate fluid replacement during initial resuscitation and during and after operation. We found evidence of complications of intravenous therapy in only two patients. One was given excessive amounts of $5 \%$ dextrose when he also required electrolytes, and he developed water intoxication. Another developed terminal pulmonary oedema during massive infusion of plasma and blood in an attempted resuscitation from an episode of postoperative collapse.

We are firmly convinced that there is considerably more danger from not giving intravenous fluids to children with peritonitis than there is from doing so.

\section{Convulsions and Hyperpyrexia}

Thirteen children had a convulsion and 19 developed hyperpyrexia (five children had both). While hyperpyrexia is occasionally mentioned as a complication of appendicitis (Benson et al., 1962) convulsions are not, and a recent book devoted to febrile convulsions in children (Millichap, 1968) does not mention peritonitis or appendicitis. Personal experience and discussion with colleagues suggest that both these complications are rare, and the incidence must be less than $1 \%$. Twenty-six of 146 children (18\%) who died postoperatively were affected, and this suggests that these complications are danger signals of great importance. While the iller children are obviously more at risk, they are just the ones unable to withstand the large metabolic demand for oxygen that is imposed. Half the children had evidence of dehydration, which may be an aggravating factor, and certainly adds to the physiological insult.

We consider that urgent measures must be taken if either of these complications appears, and control of hyperpyrexia or of convulsions must be achieved promptly. If sedation, sponging, correction of dehydration, and institution of appropriate antibiotic therapy do not effect this rapidly, then we consider that curarization, nasotracheal intubation, and positive-pressure ventilation should be started. The mechanistic approach will prevent the harmful effects of the complications while the basic pathology is being brought under control. In our personal experience of one case this line of management produced rapid improvement, which was maintained when such therapy was discontinued 12 hours later.

This approach is likely to be safer than undertaking heavy sedation in very ill children, and it seems to us that any hospital which admits children with peritonitis should be able to offer this type of intensive care.

\section{Anaesthesia}

In 19 instances we thought that anaesthesia was responsible for or contributed to the patient's death. Surprisingly only five of these children were less than 5 years old.
Seven patients had evidence of a major hypoxic episode, and in nine the technique chosen seems to us to have been inappropriate for an ill child, by reason of relative overdosage with intravenous barbiturates, or an open technique when intubation and controlled ventilation would have been preferable. Two children died during recovery, presumably from respiratory obstruction, and one developed "malignant hyperpyrexia" (Cullen, 1966). It is intended to look at these deaths in more detail elsewhere, but they emphasize the need for training and supervision of junior anaesthetists in paediatric techniques, and in general care of ill children. Some of the children might not have died from the insult imposed had they not been dehydrated, and surgeon and anaesthetist can both be faulted here.

It is appalling that deaths still occur during the recovery period, and we consider that facilities, which need not be elaborate, must be available in every theatre suite so that patients can be retained under direct supervision until they are awake. For this, and for the adequate staffing of theatres and anaesthetic rooms by day and by night, surgeons and anaesthetists must put forward reasoned cases to the hospital authorities.

Anaesthetists and obstetricians are aware of the dangers of anaesthesia in obstetrics, from the figures published in the Confidential Enquiry into Maternal Deaths. There were 50 deaths associated with anaesthesia out of a total of 579 maternal deaths in 1964-6 (8.5\%); as anaesthesia contributes 19 out of 204 deaths in children with appendicitis $(9.3 \%)$ anaesthetists and surgeons should approach this condition with even greater awareness of the problems.

\section{Other Factors}

Fifty children died later than the second postoperative day. Only 11 of these were aged less than 5, emphasizing again the higher mortality in the preoperative and perioperative period in the younger child. We had thought that chronic sepsis would be an important factor contributing to death in appendicitis, but this does not seem to be so. It may be that the factors we have discussed tend to kill the child, while sepsis results in greater morbidity rather than death. It is intended to deal with some of the purely surgical aspects of management elsewhere.

\section{Further Points}

"Toxaemia."-We have made no mention of toxaemia, though this is often referred to in accounts of acute appendicitis and in pathologists' reports. It seems to us that this expression is used to account for cardiovascular collapse in situations where there is good reason to suspect that oligaemia, dehydration, or some other remediable condition is present. We consider that this term should not be used unless appropriate antibiotic therapy has been given, fluid replacement has been adequate, acid-base abnormalities have been corrected, and adequate oxygenation has been achieved. We do not minimize the ill-effects of bacterial infection but feel that these can be reduced by appropriate management.

Type of Hospital.-From the data we have collected we cannot make comparisons between teaching and non-teaching hospitals, or children's hospitals and general hospitals. Nevertheless, it seemed to us from studying their deaths that some of these children were being cared for by staff unusued to dealing with fluid balance problems in ill children, and without some of the equipment and experience needed for dealing with the difficult situations that sometimes arose. The type of hospital probably does not matter provided the medical and nursing staff are used to dealing with ill children, and provided facilities and expertise are available for the application of what should be routine intensive care. We doubt if these conditions are likely to be met except in reasonably sized children's units. 


\section{Conclusions}

While there are still many difficulties in the diagnosis of acute appendicitis a considerable proportion of the children dying in hospital were suffering from potentially remediable effects of the disease. It seems that a more widespread application of accepted lines of treatment might reduce the mortality rate further.

Though we were looking only at deaths from acute appendicitis it is likely that the conclusions we have drawn about fluid balance, anaesthesia, and the treatment of hyperpyrexia and convulsions will be applicable to children suffering from other diseases and from trauma. This type of national medical audit should be used more extensively, on the lines of the Confidential Enquiry into Maternal Deaths.

There is a need in the health service to expend effort and money on absorbing knowledge and techniques into universal practice, and to ensure that patients are admitted to hospitals which can provide the facilities and skills appropriate to their requirements.
We wish to thank the many people who wrote to us or lent us case notes, and Mr. P, F. Jones for his helpful comments. We are also grateful to the Registrar General's staff for their valuable assistance.

\section{REFERENCES}

Benson, C. D., Mustard, W. T., Ravitch, M. M., Snyder, W. H., and Welch, K. J. (1962). Paediatric Surgery. Chicago, Year Book Medical Publishers.

Cullen, W. G. (1966). Canadian Anaesthetists' Society fournal, 13, 437. Howie, J. G. R. (1966). Lancet, 2, 1334.

Jackson, R. H. (1963). British Medical fournal, 2, 277.

Lillehei, R. C., Longerbeam, J. K., Bloch, J. H., and Manax, W. G. (1964). Clinical Pharmacology and Therapeutics, 5, 63.

Brown, J. J. M. (1956). Fournal of the Royal College of Surgeons of Edinburgh, 1, 268.

Brown, J. J. M. (editor) (1962). Surgery of Childhood. London, Arnold. Millichap, J. G. (1968). Febrile Convulsions. New York, Macmillan.

Randall, H. T., Hardy, J. D., and Moore, F. D. (editors) (1967). Philadelphia, Saunders.

Weil, M. H., and Shubin, H. (1967). Diagnosis and Treatment of Shock. Baltimore, Williams and Wilkins.

- Winsey, H. S., and Jones, P. F. (1967). British Medical Fournal, 1, 653.

\title{
Single-blind Comparative Trial of Trimethoprim-sulphamethoxazole and Ampicillin in the Treatment of Exacerbations of Chronic Bronchitis
}

\author{
D. T. D. HUGHES,* B.M., B.SC., M.R.C.P.
}

British Medical fournal, 1969, 4, 470-473

\begin{abstract}
Gummary : Fifty patients with exacerbations of chronic bronchitis were treated with either a combination of trimethoprim $320 \mathrm{mg}$. and sulphamethoxazole 1,600 mg. a day or ampicillin $2 \mathrm{~g}$. a day. The trial, carried out as a single-blind procedure, showed that the combination was more effective as judged by clinical response and reduction in sputum volume and purulence, with eradication of pathogenic organisms. No appreciable side-effects were encountered with either treatment, and it is suggested that the trimethoprim-sulphamethoxazole combination may be a safe and useful drug in the treatment of chronic bronchitis.
\end{abstract}

\section{Introduction}

Trimethoprim (2,4-diamino-5-(3,4,5-trimethoxybenzyl) pyrimidine) is a dihydrofolate reductase inhibitor (Roth, Falco, Hitchings, and Bushby, 1962). Since it selectively inhibits the bacterial rather than the mammalian enzyme it can be used as an antibacterial agent in man. Its activity is much enhanced If it is combined with a sulphonamide, and, indeed, in vitro the two can be shown to have a synergistic effect (Elion, Singer, and Hitchings, 1954 ; Bushby and Hitchings, 1968). Darrell, Garrod, and Waterworth (1968) showed that while the action of either drug is bacteriostatic, when they are used in combination this becomes bactericidal. Besides its activity against Gram-negative bacilli such as Escherichia coli and Proteus sp., the combination is also effective in vitro against such pathogens as Haemophilus influenzae and Streptococcus pneumoniae (Bushby and Barnett, 1967). It has therefore been used in the treatment of exacerbations of chronic bronchitis. Clinical trials with the combination have been reported in urinary infections (Reeves, Faiers, Pursell, and Brumfitt, 1969; Grüneberg and Kolbe, 1969), but only brief reports of its

- Senior Lecturer in Medicine, the London Hospital, London E.1. efficacy in chest disease have appeared (Drew, Hughes, Fowle, and Cassell, 1967a ; Hughes, 1968 ; Hughes, Drew, Johnson, and Jarvis, 1969). Further, in some of these a different dosage regimen was used from that now currently employed.

\section{Methods}

Fifty cases fulfilling the Medical Research Council criteria for chronic bronchitis (M.R.C., 1965) were selected. All of them had had symptoms for more than five years. There were 44 men and 6 women. They all had acute exacerbations of bronchitis leading to an increase in dyspnoea, cough, sputum volume, and purulence. The majority of them needed hospital admission, though 10 (five from each of two treatment groups) were treated as outpatients.

Comparison was made between the effect of a week's course of ampicillin $500 \mathrm{mg}$. four times a day and trimethoprim (TMP)-sulphamethoxazole (SMZ). This was administered as two Septrin tablets twice a day, each containing $80 \mathrm{mg}$. of TMP and $400 \mathrm{mg}$. of $S M Z$, so that the total daily dosage was $320 \mathrm{mg}$. of TMP and $1,600 \mathrm{mg}$. of SMZ. TMP/SMZ combinations are administered only twice daily because of their relatively long half-life in the body of 13 to 15 hours. Because of the difference in presentation (capsules as compared with tablets) and in the number of times of administration a completely double-blind trial was not feasible. It was therefore carried out as a single-blind trial. Sufficient tablets or capsules to make up a week's course of either treatment were put up in 50 numbered boxes with a slip inside instructing the patient how to take them. There were 25 one-week courses of each treatment, which were randomly allocated to the patients without the medical attendants knowing which the patient was receiving, and the code was not broken until the trial was completed or, in two instances, when the treatment had failed (see below). 